\title{
Refining Spectrum Fee to Increase Utilization Efficiency by Adopting ITU-R SM 2012-2 Case Study: Cellular Service in Indonesia
}

\author{
Ismail $^{1}$, Suhono H. Supangkat ${ }^{2}$, Hendrawan ${ }^{3} \&$ Basuki Y. Iskandar ${ }^{4}$ \\ ${ }^{1,2,3}$ School of Electrical Engineering and Informatics, Bandung Institute of Technology \\ ${ }^{4}$ Ministry of Communication and Information Technology
}

\begin{abstract}
The spectrum fees called as "Biaya Hak Pengguna Frekuensi" (BHPF) for cellular services in Indonesia are currently calculated based on apparatus, proportionally to the number of transceiver stations and radio channels. Unfortunately, the formula cannot promote the efficiency of frequency spectrum efficiency. ITU-R SM 2012-2 recommended the spectrum fee formula that can promote the efficiency; Administrative Incentives Price (AIP) also claims to promote the effectiveness of the radio spectrum utilization. By combining ITUR SM 2012-2 with AIP, the frequency fee formula can promote not only the efficiency but also the effectiveness of spectrum utilization. This paper will explain and discus the modification of ITU-R SM 2012-2 with AIP in designing the spectrum fees for cellular services in Indonesia.
\end{abstract}

Keywords: AIP; BHP-F formula; ITU-R SM 2012-2; spectrum fee; spectrum utilization.

\section{$1 \quad$ Introduction}

Spectrum is a band of electromagnetic frequencies and often used to refer the radio frequency spectrum. This band is divided into several sub-bands; the ITU's International Radio Regulations allocate the spectrum from $9 \mathrm{kHz}$ to over $275 \mathrm{GHz}$ for a range of different usage [1].

As a resource spectrum is a non-homogeneous matter and has unique characteristics; different frequencies have different characteristics hence specific frequencies are more suitable for certain usage. In general, greater bandwidth transmits more information for a given period. The quality of communication can negatively be affected by interference, i.e. decreasing voice quality or data rates connection lost/ elimination in worst cases. However, some spectrum is more susceptible to the interference than others. Interference between frequencies partly depends on the technology being used and the use of more sophisticated equipment can improve receiver performance [2].

There are four parties that have interest in spectrum management: (i) the regulator that manages and allocates the usage of spectrum, (ii) the 
telecommunications services providers that have right to use spectrum by paying the licenses fee, (iii) the users that use spectrum for their communication needs, (iv) the telecommunications equipment vendors [3].

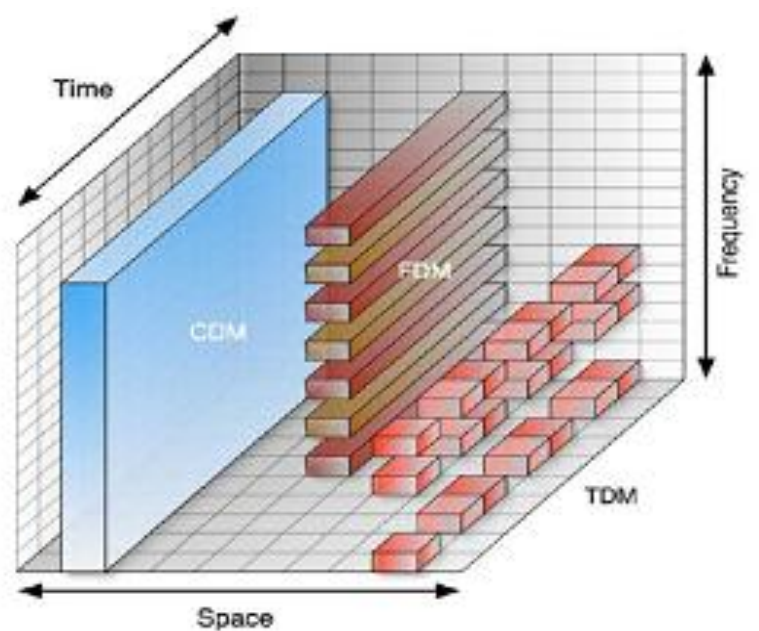

Figure 1 Three dimension of spectrum.

As illustrated in Figure 1, spectral of frequency spectrum can be represented in three dimensions: frequency dimension, space dimension and time dimension. In order to optimize the utilization of spectrum, the three dimensions should be allocated effectively. Spectrum utilization factor is expressed in the following equation [4]

$$
\mathrm{U}=\mathrm{B} \cdot \mathrm{S} \cdot \mathrm{T}
$$

where $\mathrm{U}$ is spectrum utilization that is defined to be the product of the frequency bandwidth $(B)$, the geometric or geographic space $(S)$, and the time denied to other potential users (T).

Spectrum utilization efficiency $(S U E)$ is then formulated as follows

$$
\mathrm{SUE}=\{\mathrm{M}, \mathrm{U}\}=\{\mathrm{M}, \mathrm{B} \cdot \mathrm{S} \cdot \mathrm{T}\},
$$

where $M$ is the amount of information transmitted in Erlang.

The spectrum fee should at least cover the regulator's management cost. However, its formula should be to promote the efficient use of spectrum in mind. Every year, providers that have the right to use spectrum have to pay 
spectrum fee to government and there are some methods to calculate the spectrum fee [5]:

1. Based on the spectrum management cost. Management cost consists of direct and indirect cost:

a. Direct cost, includes cost of staff time in the frequency assignment process, site clearance, interference analysis, and cost of particular of services - for example keeping the public news and entertainment channels clear, ITU and regional international consultation cost for special group of users.

b. Indirect cost, includes cost of spectrum management functions that is used to support the administration's frequency assignment process and the overhead cost of operating the administration's spectrum management procedures. These represent costs that cannot be identified to specific services or licensees such as general international consultation for example with the ITU and regional groups, propagation research covering many frequency bands and services, general spectrum monitoring, interference investigations arising from the complaints of rightful users and the cost of support staff and equipment.

2. Based on the user's gross income. The spectrum fee can be applied based on the percentage of gross income of a company. In the fee calculation, the value of gross income has to be directly related to the company's use of the spectrum to avoid the difficulty in accounting and auditing processes. India uses this method to collect the spectrum fee.

3. Based on the incentives fee. An incentive fee attempts to use price to achieve the spectrum management objectives and hence to provide some incentives to use the spectrum efficiently. Various elements of spectrum usage may be taken into consideration in the development of an approach or a formula (e.g. population density, bandwidth, frequency band, coverage area, exclusivity, power) and different formula may be required for different frequency bands and services. The incentive prices can be set specifically by government for special purpose. In UK, The government using the administrative incentives prices (AIP) based on opportunity to encourage the operator to utilize unused spectrum.

4. Based on the market. In this method, the market has the opportunity to determine the spectrum fee in an auction. The provider with a highest bid has the right to use the spectrum. 


\section{Benchmarking}

The research of spectrum fee formula has been conducted by Taiwan because the frequency usage fees in Taiwan in the past were low and did not give frequency users any incentive to invest in spectrum-efficient technologies. In addition, frequency usage fees were low compared to leased line tariffs so that users have typically preferred microwave to wire line transmission. This has led to inefficiency in spectrum usage and congestion in the microwave band. To facilitate fair access and efficient use of frequency, the current frequency usage fee structure needs to be re-examined and revised with reference to practices in other countries, including the UK, Australia, Korea, and Singapore while also taking into consideration the case of domestic frequency congestion situation in Taiwan, anticipated future spectrum needs of emerging new services, and the complaints of existing frequency users [11] (see Table 1).

Table 1 Benchmarking Spectrum Fee Formula [11].

\begin{tabular}{|c|c|c|}
\hline Country & \multicolumn{2}{|r|}{ Formula and Parameters } \\
\hline Korea & $\begin{array}{l}\text { Frequen } \\
\text { Explanations: } \\
\text { BFP } \quad \begin{array}{ll}\text { base Fee } \\
\text { antenna } \\
\text { reach of } \\
\text { BW } & \text { bandwid } \\
\text { PP } & \text { preferent } \\
\text { for } & \text { congeste } \\
& \text { frequenc } \\
\text { SUP } & \text { shared us } \\
\text { les for } & \text { shared us } \\
\text { SPP } & \text { special p } \\
& \text { Frequenc }\end{array}\end{array}$ & $\begin{array}{l}\text { Isage fee }=\text { BFP } \times(\sqrt{ } W+B W) \times \text { PP } x \text { SUP } \times \text { SPP. } \\
\text { rameter is } 2000 \text { Korean Yen (less than } \$ 2) \\
\text { ssion power (Watts) Taking the square root of the emission power to reflect the } \\
\text { io coverage } \\
\text { kHz) } \\
\text { parameter. It varies with different frequency bands. The parameters are higher } \\
\text { equency bands. In order to encourage developing radio applications in the high } \\
\text { ands, the parameters will be relatively low } \\
\text { arameter. The parameters will be higher for exclusive use of frequencies; and } \\
\text { f frequencies } \\
\text { ose parameter. There are different parameters for different radio service types. } \\
\text { used for public services should have a small parameter value }\end{array}$ \\
\hline Singapore & $\begin{array}{l}\text { Singapore use } \\
\text { as below : } \\
\text { Bandwidth }<1 \mathrm{MHz} \\
\text { Bandwidth } \geq 1 \mathrm{MHz}\end{array}$ & $\begin{array}{l}\text { spectrum fee formula based on bandwidth consumption } \\
300 \text { Singapore dollar per } 25 \mathrm{kHz} \\
12,000 \text { Singapore dollar for the first MHz, an extra } 300 \text { Singapore dollar for } \\
\text { each additional } \mathrm{MHz} \\
3500 \text { Singapore dollar } \\
\text { for frequency band }<20 \mathrm{MHz} \\
6200 \text { Singapore dollar } \\
\text { for frequency band } \geq 20 \mathrm{MHz}\end{array}$ \\
\hline Australia & $\begin{array}{l}\text { Australia uses } \\
\text { Frequen } \\
\text { The parameters are ex } \\
K \\
\mathrm{Si} \quad \text { base fee } \\
\text { spectrum }\end{array}$ & $\begin{array}{l}\text { spectrum fee formula as below } \\
\text { sage fee }=K \times(\mathrm{Si}, \mathrm{Gi}) \times \mathrm{Bi} \times \mathrm{Ai} \text {. } \\
\text { ined below: } \\
\text { ameter } \\
\text { cation }\end{array}$ \\
\hline
\end{tabular}




\begin{tabular}{|c|c|}
\hline Country & Formula and Parameters \\
\hline & 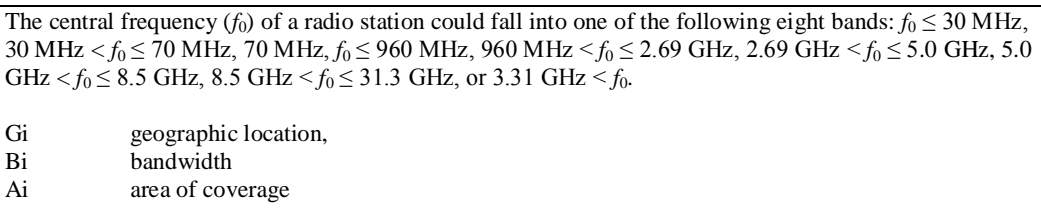 \\
\hline $\mathbf{U K}$ & $\begin{array}{l}\text { The UK frequency authority (Radio Communications Agency of UK, } \\
\text { 1999; Green, 1999) considers the value of a spectrum to be the difference } \\
\text { between the marginal utilization generated from the spectrum and the } \\
\text { marginal cost of obtaining the spectrum. This difference is the users' } \\
\text { willingness to pay for the frequency usage fee. At times when demand for } \\
\text { frequency is higher than its supply, the frequency usage fee can be } \\
\text { measured as the unrealized cost savings resulting from failure to obtain } \\
\text { such frequency. It can also be regarded as an opportunity cost, which is } \\
\text { the cost difference between using the frequency vs. using other } \\
\text { alternatives, like public radio services, different transmission } \\
\text { technologies, or using frequencies in different frequency bands. } \\
\text { Frequency usage fees may also be levied in accordance with revenues or } \\
\text { profits. However, the frequency usage fees may constitute merely a small } \\
\text { part of one user's total revenue while being a large part of another user's } \\
\text { revenue. Therefore, associating frequency usage fee with a percentage of } \\
\text { a user's revenue is not equitable among all users. }\end{array}$ \\
\hline Taiwan & 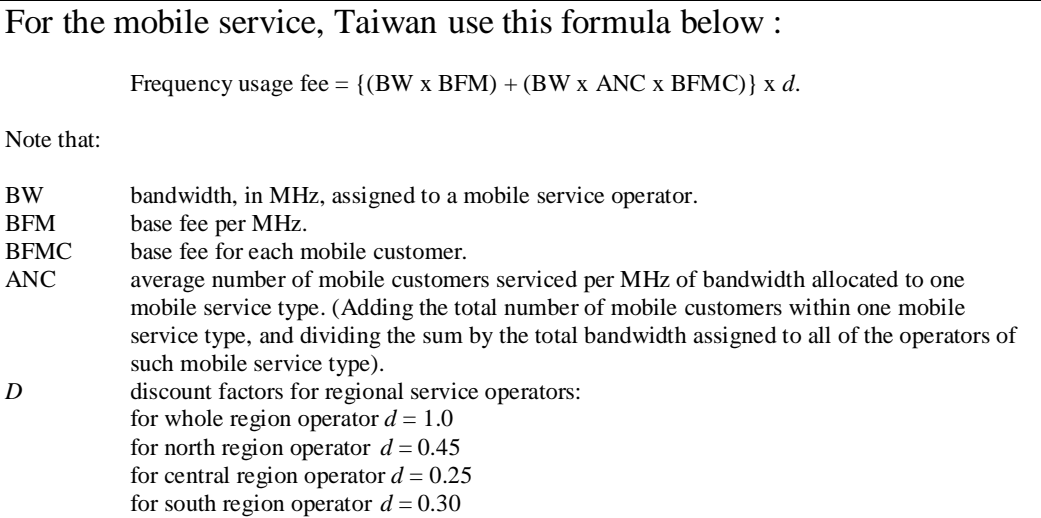 \\
\hline
\end{tabular}

The revised frequency usage fee charging system for Taiwan has the following advantages:

a. For each radio service type and each bracket of frequency band, the frequency usage fees are calculated from several concise equations of consistent structure, which generate fees directly proportional to the bandwidth consumed and power emitted. Instead of looking into 


\begin{tabular}{l|l}
\hline Country & \multicolumn{1}{c}{ Formula and Parameters } \\
\hline & $\begin{array}{l}\text { oversimplified and discrete rate tables to figure out usage fees, these } \\
\text { equations help make the fee pricing system fairer and more easily } \\
\text { computerized }\end{array}$ \\
b. $\quad \begin{array}{l}\text { Charging less for frequencies in higher frequency bands than for } \\
\text { frequencies in lower frequency bands is simply done by setting } \\
\text { descending base fee parameters for the respective fee equations in } \\
\text { the ascending frequency bands. }\end{array}$ \\
c. $\begin{array}{l}\text { A few categories of usage fees are raised to reflect the true value of } \\
\text { certain commercial radio services, such as public mobile phone } \\
\text { service, or to relieve congestion in the frequency band of microwave } \\
\text { transmission. On the other hand, special discounts are given to public } \\
\text { service bureaus such as the police department, fire department, } \\
\text { emergency rescue organizations, etc. Educational, experimental, and } \\
\text { research use of frequencies are also heavily discounted. }\end{array}$ \\
\hline
\end{tabular}

The formula implemented by those countries are different based on situation in each country such as providers competition, geography, population, government expectation of income from spectrum fee, etc. The aim is the same; to create a fair and technologically neutral formulating frequency spectrum fee to increase spectrum utilisation efficiency.

The Taiwan's case study shows that power emission is not an important factor in frequency fee calculation based on apparatus; the fee is more afffected by bandwidth consumpetion and number of user achieved. The formula used in Taiwan also shows AIP, which gives discount factor for regions with different economic level.

\section{Calculation of Existing Spectrum Fee in Indonesia}

In Indonesia, spectrum fee namely as "Biaya Hak Pengguna Frekuensi" or BHP-F is comprised of the following items [6].

a. the type of radio frequency;

b. the width of band and/or channel of radio frequency;

c. the transmission power;

d. the location;

e. the market interest.

The formula of BHP-F is written as below: 


$$
B H P-F=\left(\frac{l b * H D L P * b+l p * H D D P * p}{2}\right),
$$

where $H D D P$ is reference for transmission power (rupiah unit), HDLP is reference for bandwidth (rupiah unit), $p$ is EIRP of transmitter $(\mathrm{dBm}), b$ is bandwidth $(\mathrm{kHz}), I b$ is bandwidth index, and $I p$ is power index.

Here, HDDP and HDLP are determined from the classification of frequency bandwidth and geographical zone, respectively. The bandwidth index (Ib) and power index (Ip) are classified by the type of radio communication services. Geographical zone consists of 5 zones, which depend on the economic and population growth factors; for example in satellite networks (space segment) the zone is assumed as Zone 3 (average zone) since it covers the whole country.

To illustrate how the BHP-F of some radio frequency spectrum calculation per each station and each RF channels works, an example is explained as follows.

A station uses GSM-900, $200 \mathrm{kHz}$ of bandwidth, $53 \mathrm{dBm}$ of EIRP of transmitter, type of transceiver as transmitter, and is located in Zone 1, then the $\mathrm{BHP}$ of radio frequency spectrum is:

$$
B H P-F=\left(\frac{8.79 * 11772 * 200+4.2 * 109481 * 53}{2}\right)=45 \text { Billion }
$$

The BHP-F of radio frequency spectrum is imposed at the time of license issuance and paid annually in advance. However, the use of radio frequency spectrum for specific purposes is exempted from the imposition of BHP-F rule, such as: for state's security and defense purpose, special official services, governmental agencies purpose used by the representatives of foreign countries on the basis of reciprocity principle [7].

\section{Weakness of Cellular Spectrum Fee Based on Apparatus}

There are some weaknesses of BHP-F calculation for cellular services in Indonesia based on Apparatus:

a. No difference in fee incentive for using low or high frequency.

It is wellknown that the type of services categorized as mass services such as broadcasting and cellular communication are highly competitive and profitable. Hence, the interference and type of propagation at low frequency is better than the high one as the bandwidth at low frequency is scarce. Cellular services use the frequency in UHF band (300-3000 MHz), while the HDDP and HDLP as shown in Table 2 have the same value for all frequencies in that band. In the implementation there is no difference 
between the low and high frequencies that is not matched with the BHP-F calculation. Ideally, there should be a different incentive fee for the low and high frequency user where the lower frequency user has to pay more than the higher one.

Table 2 HDDP and HDLP lookup table in UHF band (300 MHz-3000MHz).

\begin{tabular}{l|rrrrrr}
\hline & Band & \multicolumn{1}{c}{ Zone I } & \multicolumn{1}{c}{ Zone 2 } & Zone 3 & Zone 4 & \multicolumn{1}{c}{ Zone 5 } \\
\hline HDLP & UHF & 11,772 & 9,418 & 7,063 & 4,709 & 2,354 \\
HDDP & UHF & 109,481 & 87,585 & 65,688 & 43,792 & 21,896 \\
\hline
\end{tabular}

b. No Compensation or Penalty for Unutilized Licensed Spectrum.

Since cellular service providers have spectrum licenses paid annually, they have a special right to use the licensed spectrum exclusively and other providers are not allowed to use it. In some cases, some licensed spectrums have not been utilized by their owner. However, those spectrums cannot be used by others although they have an opportunity to utilize it. The compensation or penalty for unutilized licensed spectrum has not expressed in the BHP-F formula since it calculates only the number of stations and channel usage. There should be some compensation or penalty for the provider that has not utilized their spectrum effectively to increase utilisation.

c. Technology Dependency.

The other weakness of BHP-F calculation for cellular services is technology dependency. From the BHP-F formula, it should be noted that the parameter of bandwidth index (Ib) and power index (Ip) can be categorized by the type of service related with the technology used as tabulated in Table 3.

Table 3 Ib and Ip in GSM and FWA.

\begin{tabular}{llcc}
\hline \multicolumn{2}{c}{ Type of service } & Ib & Ip \\
\hline Cellular FDMA (AMPS. NMT) & Base + out station & 8.210 & 0.630 \\
Cellular TDMA (GSM,DCS \& PCS) & Base + out station & 8.790 & 4.200 \\
Cellular DS-CDMA (IS95) & Base + out station & 3.400 & 11.710 \\
WLL FDMA & Base + remote/out station & 1,360 & 0,110 \\
WLL TDMA & Base + remote/out station & 0,230 & 0,490 \\
WLL DS-CDMA & Base + remote/out station & 0,070 & 0,490 \\
\hline
\end{tabular}

d. Unfairness.

The spectrum fee formulated in BHP-F formula is calculated each station and each RF channel; for the providers that use more bandwidth, they usually pay no more for the excess bandwidth. From Table 4 for price per $\mathrm{MHz}$ comparison, it is shown that provider $\mathrm{J}$ that uses $30 \mathrm{MHz}$ pays lower than provider $\mathrm{K}$ that uses only $20 \mathrm{MHz}$ although they have the same 
national right. There is unfairness caused by BHP-F formula since the provider has the ability to deliver more service with more bandwidth. To eliminate that unfairness, price per $\mathrm{MHz}$ for every provider must be equal because all providers have the same right and opportunity to deliver as much information.

Table 4 Price per MHz for GSM and FWA provider [9].

\begin{tabular}{lccrr}
\hline Technology & User & BW (MHz) & BHP-F 2007 (Rp) & BHP-F / BW (Rp/MHz) \\
\hline & B & 14.76 & $48,310,547,876$ & $3,273,072,349$ \\
CDMA-800 & C & 14.76 & $36,485,030,866$ & $2,471,885,560$ \\
& D & 9.84 & $38,835,940,774$ & $3,946,741,949$ \\
& E & 4.92 & $2,953,073,559$ & $600,218,203$ \\
\hline & G & 80 & $1,331,215,092,932$ & $16,640,188,662$ \\
GSM-900/ & H & 65 & $736,531,891,098$ & $11,331,259,863$ \\
GSM-1800 & I & 30 & $328,389,937,561$ & $10,946,331,252$ \\
& J & 30 & $24,647,702,466$ & $821,590,082$ \\
& K & 20 & $74,167,162,639$ & $3,708,358,132$ \\
\hline
\end{tabular}

e. The advanced technologies in communication services make it possible that more channel are available from the same bandwidth. The spread spectrum and multi-hoping technology make the calculation of bandwidth currently in used imprecise, and at the end, the spectrum fee is difficult to calculate accurately using the BHP-F formula.

f. The BHP-F formulation which was calculated based on base transceiver station (BTS) makes the spectrum fee increases according to the increase of user and traffic. This situation is contradictive with the attempt of improving service quality and optimum spectrum utilization.

Apparatus system used in the cellulair provider calculation was thought to cause spectrum utilisation only in Java which has high level of economic acitivity and dense population as shown in Figure 2. This is the result of using the apparatus system that calculates fee based on channel number being used while the opportunities to use channel in less populated area are already closed. This condition makes providers build facilities only in financially viable area. The use of emission do not guarantee that providers will have more profit as the business revenue comes form the number of users not the emission power. Apparatus systems are more suitable to be used in poin to point communication system where emission affects area range. 


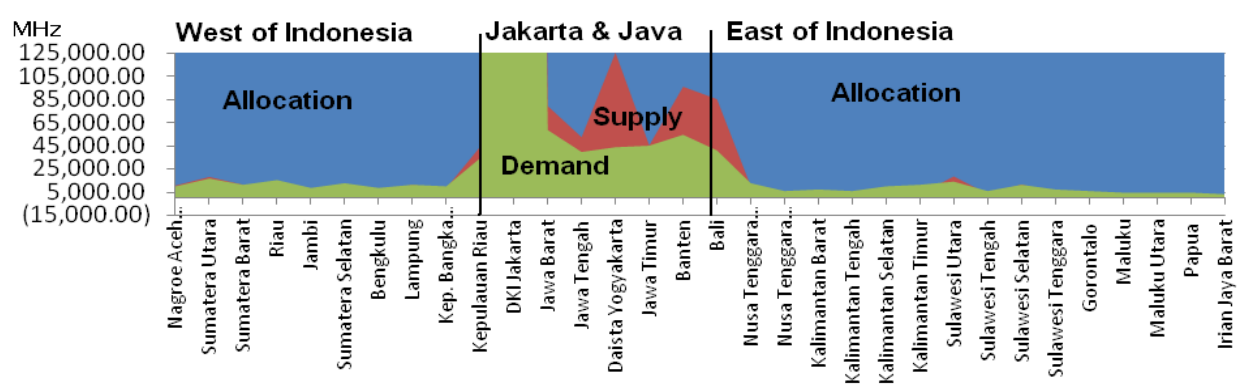

Figure 2 Spectrum Allocation vs Supply vs Demand in Indonesia.

\section{$5 \quad$ Recommendation from ITU-R SM.2012-2}

ITU-R SM. 2012-2 - Economic aspects of spectrum management was issued in 1998. In that recommendation, ITU has proposed an analytical model for calculating license fees on the basis of specified incentives that are designed to promote efficient spectrum use [5]. It was also developed in the framework of the BDT Asia and Pacific Project on Spectrum Validation and Licensing, Bangkok, 2000. The model is derived from the conceptual base that there is a distinct need to price spectrum and that the pricing of spectrum resources should reflect more than administrative convenience. The purpose of this model is to increase spectrum utilization efficiency. It is designed to introduce nondiscriminatory access to the spectrum for various categories of users, stimulate the use of less congested (particularly - higher) frequency bands, stimulate harmonized development of radio communication services throughout the country, and cover the cost of spectrum management. It includes the consideration of the phased development and/or maintenance of spectrum management and monitoring facilities and reimbursement of expenditures of a national telecommunication administration including its international activities within ITU.

The proposed spectrum payment algorithm includes the following steps:

a. Determination of annual expenditures of the state on management of actually used spectral resource and determination of the common value of the annual payments for all spectral resources.

Here, the total amount of the annual payments for spectral resource (Can) can be collected from all users where they come from share of the sum that is necessary for covering expenditures of the state on all national and international spectrum management activities, net income of the state - if applied-, etc.

$$
C_{a n}=C_{1}+C_{2}-I_{a n}
$$


where $C_{1}$ is the cost of managing the spectrum at national as well as international level; $C_{2}$ is the country's net revenue (optional) and $I_{a n}$ is the annual inspection cost.

b. Determination of the value of the spectral resource used by each radio station and, through their summation, by all stations registered in a national Spectrum Management Database.

This step is to determine the spectral resource value used by each user and then by all users. For any $i$-th frequency assignment (from their total amount $\mathrm{n}$ incorporated in the national database), the three-dimensional value of the spectral resource is denoted as $W$ i. This spectral resource is the multiplication of frequency resource, territorial resource and time resource. A frequency resource $F i$ used by $i$-th emission is determined by necessary bandwidth of the emission (MHz), calculated in accordance with Recommendation ITU-R SM.1138, taking into account that an occupied bandwidth of an emission should be equal to its necessary bandwidth [8].

$$
W_{i}=\alpha_{i} \times \beta_{i} \times\left(F_{i} \times S_{i} \times T_{i}\right)
$$

where $F_{i}$ is the frequency being used, $S_{i}$ is the used area, $T_{i}$ is the used time, $\alpha_{i}$ is the weighted coefficient such as commercial value, social value, etc, $\beta_{i}$ is the weight factor for spectrum exclusivity.

$$
F_{i}=\chi B_{n i} \quad \mathrm{MHz}
$$

where $B_{n i}$ is emission bandwidth; $\chi$ is adjustment $(0 \leq \chi \leq 1)$ which can be used to differentiate type of services such as radio, TV, radar, etc with the same power.

$$
S_{i}=b_{i j} \cdot s_{i} \quad\left(\mathrm{~km}^{2}\right) \quad 1 \leq j \leq m
$$

where $S_{i}$ is the area covered by emission in $\mathrm{km}^{2} ; b_{i j}$ is the weighted factor for category of spectrum utilisation and $m$ is the number of category

$$
W=\sum_{j=1}^{n} W_{j}\left(\mathrm{MHz} \cdot \mathrm{km}^{2} \cdot 1 \text { year }\right)
$$

where $W \mathrm{i}$ is the $i^{\text {th }}$ spectrum and $n$ spectrum number being registered.

A territorial resource $S i$ used by $i$-th emission is determined by the territory actually occupied (covered) by the emission in accordance with certain criteria $\left(\mathrm{km}^{2}\right)$, and weighting coefficient which depends on the $j$-th category of the territory actually occupied by the emission and also number 
of categories. The number of categories $m$ and the relevant values of the weighting coefficients $b \mathrm{j}$ should be set out by a national telecommunications administration. These categories can take into account density of population and/or level of economic (industrial and/or agricultural) development of various regions of a country.

A time resource $T i$ used by $i$-th emission is determined as not more than one year and for each frequency assignment represents a fraction of time related to one year, determined in that or another way, during which the radio transmitter operates in accordance with terms set out in the relevant license.

For example, if a particular TV transmitter in accordance with terms of its license is operating only $16 \mathrm{~h}$ per day throughout the whole year, than $T 1=$ 0.67 year. If another 16/24 transmitter (for example an HF one used for geological expedition), in accordance with terms of its license can operate totally only 3 months per year, then: $T 1=3 / 12=0.35$ year.

c. Determination of the price for a unit of the spectral resource.

In this step, it is possible to determine the price of $\Delta C a n$ for a qualified unit of the spectral resource where it presents as units of a national currency $/(\mathrm{MHz} \cdot \mathrm{km} 2 \cdot 1$ year $)$

$$
\Delta C_{a n}=L C_{a n} / W \quad \mathrm{IDR} /\left(\mathrm{MHz} \cdot \mathrm{km}^{2} \cdot 1 \text { year }\right)
$$

where $L$ is the adjustment factor, which is determined by the government for the next annual budget.

d. Determination of the annual payment for a specific user on a differential and non-discriminatory basis, which is determined from the actual value of used spectral resource.

General weighing coefficient can be presented from taking into account commercial value of the spectrum range used, social factor, features of transmitter location, the complexity of spectrum management functions and other coefficient (coefficients) that can be introduced by an administration reflecting its specific needs. Another weighting coefficient is exclusive of the frequency assignment.

According to equation above the price $\Delta C a n$ for the qualified unit of the spectral resource is determined. Equation above gives the value of the spectral resource $W i$ used for a particular $i$-th frequency assignment. Based on this, the amount of the annual payment $C$ i from the specific user of the spectrum for this frequency assignment can be determined as:

$$
C_{i}=C_{a n} \cdot W_{i}
$$




\section{Formula Calculation of ITU-R SM 2012-2 for Cellulair in Indonesia}

By using the recommendation from ITU-R SM 2012-2, the spectrum fee is refined by adopting the recommended model. However, we are limiting adoption of the model in the simulation only for cellular service. In this simulation, the spectrum that has to be paid by providers depends on their spectral. The steps of simulation are outlined below.

a. Define expenditures and income of a state related with spectrum management.

The total amount of the annual payments for spectral resource $\left(C_{a n}\right)$ comes from the total annual BHP that provider must pay on 2007 for cellular service (not included 3G) as 2.6 Billion Rupiahs. The value of this BHP-F is the non tax income, which is fixed and is not allowed to be lowered because it is vital for the government.

b. Define a spectral.

Weighting coefficient bj is defined as population density, area $(S)$ is defined as area per-region and uses the $j$-th category where for $1 \leq j \leq m, m$ is 5 regions as stated above as shown in Table 5.

Table 5 Weighting coefficient (b) and Area (S).

\begin{tabular}{clcrr}
\hline $\begin{array}{c}\text { No } \\
(\mathbf{j})\end{array}$ & \multicolumn{1}{c}{ Region } & $\begin{array}{c}\text { Area }\left(\mathbf{k m}^{2}\right) \\
(\mathbf{S})\end{array}$ & Population & $\begin{array}{c}\text { Density (pop/km2) } \\
(\mathbf{b})\end{array}$ \\
\hline 1 & SUMATERA & 450,207 & $44,680,030$ & 99.24332 \\
2 & JAWA-BALI-NT & 199,020 & $138,645,203$ & 696.63910 \\
3 & KALIMANTAN & 507,421 & $11,694,255$ & 23.04647 \\
4 & SULAWESI & 195,651 & $15,399,160$ & 78.70726 \\
5 & MALUKU PAPUA & 637,517 & $4,471,434$ & 7.01383 \\
\hline
\end{tabular}

Value of $\alpha$ is 1 because the cellulair services in this case study is commercial area and $T$ value is 1 becuase of working hours of $24 \times 365$ days a year continuosly.

Cellular works in spectrum band of CDMA-450 MHz, CDMA-800 MHz, GSM$900 \mathrm{MHz}, \mathrm{GSM}-1800 \mathrm{MHz}$ and CDMA-1900 MHz. Every band has its own characteristic, whilst the propagation of each spectrum depends on the used band. We adopt the calculation model shown in mobile radio service Annex 1 part 4 of ITU-R SM 2012-2.

Each range $(R)$ is found using Okumura Hatta formula as below [10]: 


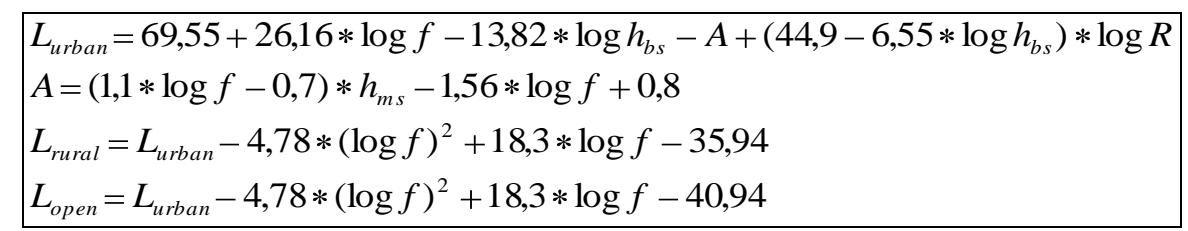

where $\quad: L$ is channel attenuation $(\mathrm{dB})$

$f$ is the frequency (Mhz)

$h_{b s}$ is height of base station antenna (m)

$h_{m}$ is height of mobile antenna (m)

$R$ is radius of cell $(\mathrm{km})$

The model assumes that the existence of homogeneous urban development is in limits of the service area using environment coefficient as shown in Table 6 .

Table 6 Environment coefficient of Urban.

\begin{tabular}{|c|c|c|c|c|c|c|}
\hline $\begin{array}{c}\text { Environment } \\
\text { Type } \\
\text { ("morphology") }\end{array}$ & $\begin{array}{c}\text { Building } \\
\text { Median } \\
\text { Loss, dB }\end{array}$ & $\begin{array}{l}\text { Building } \\
\text { Std. } \\
\text { Dev, dB }\end{array}$ & $\begin{array}{c}\text { Outdoor } \\
\text { Std. } \\
\text { Dev, dB. }\end{array}$ & $\begin{array}{l}\text { Composite } \\
\text { Standard } \\
\text { Deviation }\end{array}$ & $\begin{array}{c}\text { Desired } \\
\text { Reliability } \\
\text { at Cell } \\
\text { Edge,\% }\end{array}$ & $\begin{array}{l}\text { Fade } \\
\text { Margin, } \\
\text { dB. }\end{array}$ \\
\hline Urban & 15 & 8 & 8 & 11,31 & $75,0 \%$ & 7,63 \\
\hline
\end{tabular}

The heights of transmitting and receiving antennas are in limits $20-200 \mathrm{~m}$ and $1.5-10 \mathrm{~m}$, respectively.

Using forward and reverse budget calculation, propagation range for each frequency channel from $400 \mathrm{MHz}$ up to $2100 \mathrm{MHz}$ is shown in Figure 3.

Using best-fit logarithmic trendline method, the above samples give natural logarithmic function, which is used as adjustment for frequency $\left(X_{\mathrm{i}}\right)$ as follows:

$$
X_{\mathrm{i}}=1.56 \ln \left(F c_{\mathrm{i}}\right)+12.77 .
$$

Where $F c i$ is spectrum frequency channel.

From the data above, $W i$ is determined as follows.

$$
W \mathrm{i}=F_{\mathrm{i}} \cdot S_{\mathrm{i}}=X_{\mathrm{i}} \cdot \mathrm{Bn}_{\mathrm{i}} \cdot b_{\mathrm{i}} \cdot S_{\mathrm{i}}
$$

where $X_{i}$ is the adjustment of frequency, $B n_{i}$ is the bandwidth of spectrum, $b_{i}$ is the population density of weighting coefficient, and $s_{i}$ is the coverage area $\left(\mathrm{km}^{2}\right)$ 


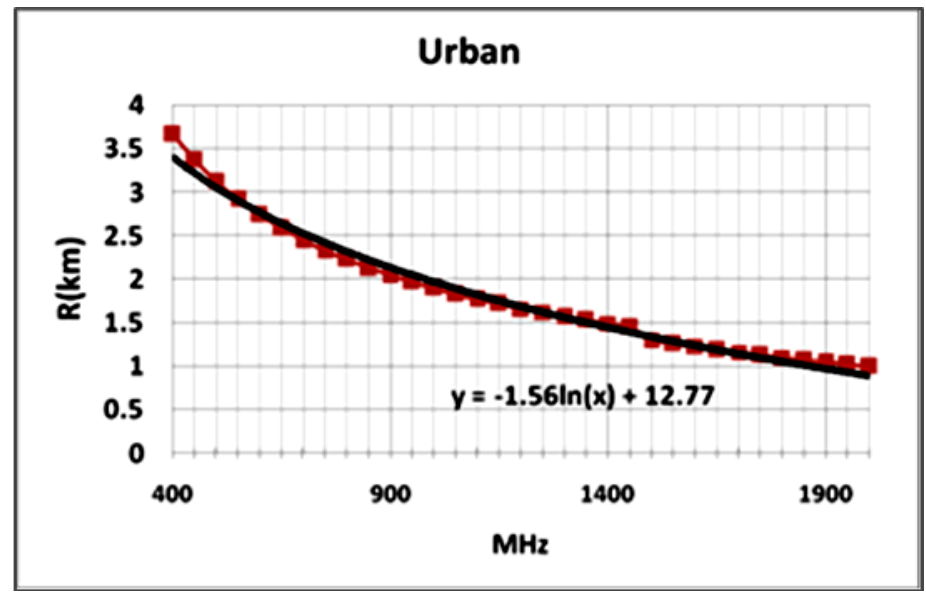

Figure 3 Frequency vs Range on band $400 \mathrm{MHz}-1900 \mathrm{MHz}$.

Ideal condition for this study is when all spectrums have been utilised in all regions to calculate $W$ in order to find the spectral value. $W$ value for all spectrums that is assigned to cellulair provider is shown in Table 7.

Table 7 W total for all cellular providers.

\begin{tabular}{|c|c|c|c|c|c|c|}
\hline Technology & Provider & Fc & Bn (MHz) & $\mathbf{X}$ & b.s $\left(\mathrm{x10}^{6}\right)$ & $\mathbf{W}$ \\
\hline CDMA-450 & $\mathrm{A}$ & 450 & 15 & 3.24 & 214,9 & $10,442,280,210$ \\
\hline \multirow{4}{*}{ CDMA-800 } & B & 800 & 14.76 & 2.34 & 214,9 & $7,428,318,492$ \\
\hline & $\mathrm{C}$ & 800 & 14.76 & 2.34 & 214,9 & $7,428,318,492$ \\
\hline & $\mathrm{D}$ & 800 & 9.84 & 2.34 & 214,9 & $4,952,212,328$ \\
\hline & $\mathrm{E}$ & 800 & 4.92 & 2.34 & 214,9 & $2,476,106,164$ \\
\hline \multirow[t]{4}{*}{ CDMA-1900 } & $\mathrm{F}$ & 1900 & 12.5 & 0.99 & 214,9 & $2,666,273,761$ \\
\hline & \multirow{2}{*}{$\mathrm{G}$} & 900 & 15 & 2.16 & 214,9 & $6,956,840,874$ \\
\hline & & 1800 & 65 & 1.08 & 214,9 & $15,042,739,995$ \\
\hline & \multirow{2}{*}{$\mathrm{H}$} & 900 & 20 & 2.16 & 214,9 & $9,275,787,832$ \\
\hline \multirow{5}{*}{$\begin{array}{c}\text { GSM } 900 / \\
1800\end{array}$} & & 1800 & 45 & 1.08 & 214,9 & $10,414,204,612$ \\
\hline & \multirow[t]{2}{*}{ I } & 900 & 15 & 2.16 & 214,9 & $6,956,840,874$ \\
\hline & & 1800 & 15 & 1.08 & 214,9 & $3,471,401,537$ \\
\hline & $\mathrm{J}$ & 1800 & 30 & 1.08 & 214,9 & $6,942,803,074$ \\
\hline & K & 1800 & 20 & 1.08 & 214,9 & $4,628,535,383$ \\
\hline & & & & & Total & $99,082,663,627$ \\
\hline
\end{tabular}

c. Define price for the qualified unit of used spectral resource.

From equation above we define:

$$
\begin{aligned}
& \text { Can }=2,659,647,996,865 \text { IDR } \\
& W=99,082,663,627 \mathrm{MHz} / \mathrm{km} 2 / \text { year }
\end{aligned}
$$


For 2007 , we set $\mathrm{L}=1$, so

$$
\Delta C_{\text {an }}=\frac{2,659,647,996,865}{99,082,663,627}=26.8 \mathrm{IDR} / \mathrm{MHz} / \mathrm{km} 2 / \text { year }
$$

d. Annual fee for particular frequency assignment of every provider.

By using the equation above, in 2007 every provider should pay as shown in Table 8.

Table 8 Can per operator that should be paid.

\begin{tabular}{|c|c|c|c|c|}
\hline Technology & Provider & Band & BW (MHz) & $\mathrm{C}_{\mathrm{an}}$ (IDR) \\
\hline CDMA-450 & $\mathrm{A}$ & 450 & 15 & $280,299,203,851$ \\
\hline \multirow{4}{*}{ CDMA-800 } & $\mathrm{B}$ & 800 & 14.76 & $199,396,273,341$ \\
\hline & $\mathrm{C}$ & 800 & 14.76 & $199,396,273,341$ \\
\hline & $\mathrm{D}$ & 800 & 9.84 & $132,930,848,894$ \\
\hline & $\mathrm{E}$ & 800 & 4.92 & $66,465,424,447$ \\
\hline CDMA-1900 & $\mathrm{F}$ & 1900 & 12.5 & $71,570,040,017$ \\
\hline \multirow{6}{*}{ GSM 900 / 1800} & G & $\begin{array}{c}900 \\
1800\end{array}$ & $\begin{array}{l}15 \\
65\end{array}$ & $590,528,589,369$ \\
\hline & $\mathrm{H}$ & $\begin{array}{c}900 \\
1800\end{array}$ & $\begin{array}{l}20 \\
45\end{array}$ & $528,532,953,961$ \\
\hline & \multirow[b]{2}{*}{ I } & 900 & 15 & \multirow{2}{*}{$279,922,391,132$} \\
\hline & & 1800 & 15 & \\
\hline & $\mathrm{J}$ & 1800 & 30 & $186,363,718,942$ \\
\hline & $\mathrm{K}$ & 1800 & 20 & $124,242,479,295$ \\
\hline
\end{tabular}

Comparing old formula in 2007 and the new one using ITU-RS M.2012-12 in a ideal condition in which all providers are applying spectrum utilisation in all regions, it is shown that provider $\mathrm{A}$ to $\mathrm{F}$ and $\mathrm{J}$ and $\mathrm{K}$, which use CDMA 450,800 and $1900 \mathrm{MHz}$ and GSM 1800 have to pay higher fee if current formula is applied, while provider G-I, which use GSM 900 and 1800 have to pay lower fee (see Figure 4). The reason is that provider G,H, and I is a mature provider where frequency channel is utilised higher than the others and pay higher fee than the average fee paid by each provider. The new formula will encourage other providers other than the 'big three' to increase utilisation and increase more users and traffic while compensating the cost of spectrum fee, which is lower than current situation. This shows the new formula will promote the increase efficiency in spectrum utilisation. 


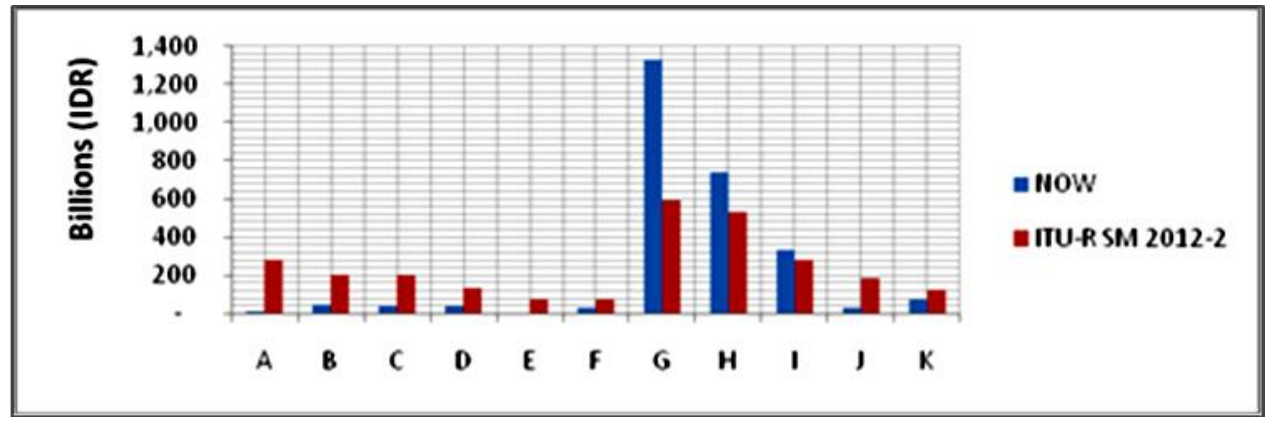

Figure 4 Spectrum fee paid by each operator.

\section{$7 \quad$ Proposed Spectrum fee Formula}

As explained above, the ITU SM 2012 uses BHP-F calculation based on bandwidth combined with potential economic value, which is unique in frequency band and spectrum spectral being used.

The problem might occur if ITU SM.2012 is implemented directly because BHP-F is calculated based only on frequency being used, and the effort to increase service development in region of economically unfeasible in Indonesia is difficult to execute.

Additional program as incentive to increase spectrum utilisation and nunber of users especially in economically unfeasible area such as in East part of Indonesia, will be introduced to solve the problem. This incentif is based on AIP (Administrative Incentive Price) method where government applies an incentif as administrative procedures. Spectrum exclusivity value is also being considered as fee will be calculated not only based on spectrum in use, but the unused spectrum is also calculated because it hinders other providers to utilise the spectrum.

Below is several alternatives of BHP-F formula. The proposed method is the modification of ITU-R SM2012 formula, where several coefficents are used or redefined to give incentive while at the same time holding the principle of neutrality to technology and fairness to unique technological opportunity that charaterize the spectrum bands.

a. ALTERNATIVE-1. Value of $S$ is based on area of spectrum being utilised owned by each provider.

$$
\text { Spectrum_fee }=\mathrm{X} * \mathrm{~B} * \mathrm{~S}_{\text {used }} * \text { unit_price }
$$


Where $\mathrm{X}$ is frequency band utilisation coefficient, B is the bandwidth, and $S_{\text {used }}$ is the potential number of user in the region being utilised.

b. ALTERNATIVE-2. Value of $S$ is found by adding AIP coefficient based on utilised area of each provider and its right, 0.3 for right, and 0.7 for utilised area.

$$
\text { Spectrum_fee }=\mathrm{X} * \mathrm{~B} *\left(0.3 * \mathrm{~S}_{\text {right }}-0.7 * \mathrm{~S}_{\text {used }}\right) * \text { unit_price }
$$

Where $\mathrm{X}$ is coefficient frequency band, B is the bandwidth channel, and $S_{\text {used }}$ is potential number of users in the utilised region, and $S_{\text {righ }}$ is the potential number of users in area with the right being hold by the provider.

c. ALTERNATIVE-3. S value is the potential number of users which can be achieved converted to realized users which has been achieved.

$$
\text { Spectrum_fee }=X * B * S_{\text {real }} * \text { unit_price }
$$

Where $\mathrm{X}$ is the coefficient of frequncy band utilisation, $\mathrm{B}$ is the bandwidth channel, and $S_{\text {real }}$ is number of users acheved.

Comparing all three modifications using the redefinition above to the old BHPF and ITU-R.SM.2012-2 shows that alternative-3 give lower gap to the difference between the two, showing direct relation between channel being used and the number of customers (see Figure 5).

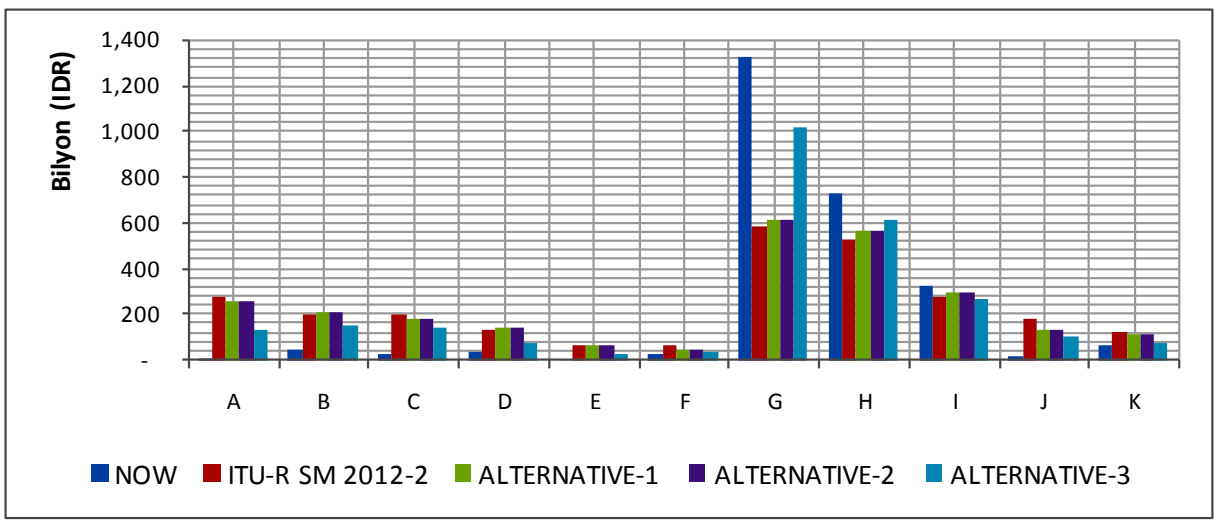

Figure 5 Comparison of calculation of spectrum fee.

Other than the above methods, incentives can also be given based on the highest service traffic record. This incentive needs data of incoming and outgoing 
traffic and then divided them with the bandwith being used and coverage service area. Figure 6 shows the traffic record per Mhz per square km.

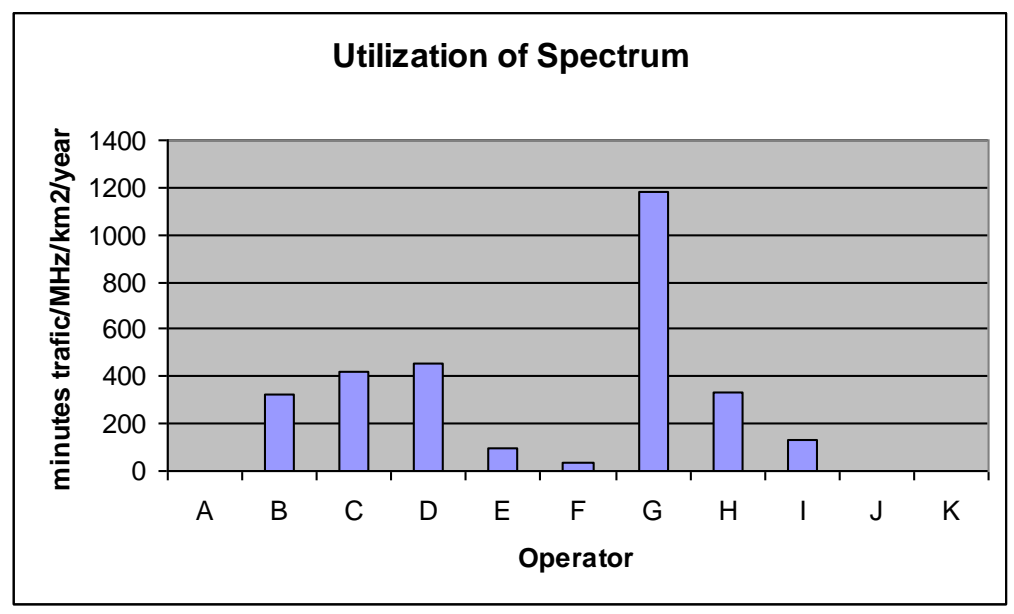

Figure 6 Scenario of calculation spectrum fee with erlang/MHz/km².

By using alternative-2 and setting upper limit of ideal traffic per $\mathrm{MHz}$ per $\mathrm{km}^{2}$, a provider which has achieved the upper limit will get the $\mathrm{Q}$ reduction factor, which is the difference of current traffic per MHz per $\mathrm{km}^{2}$ from the ideal traffic being set.

$$
\text { Spectrum_fee }=X * B *\left(0.3 * S_{\text {right }}+0.7 * S_{\text {used }}\right) * Q * \text { Unit_price }
$$

Where $\mathrm{X}$ is the frequency band coefficient, $\mathrm{B}$ is the channel width, $\mathrm{S}_{\text {used }}$ is the potential number of users in the utilised region, $S_{\text {right }}$ is the potential number of users in the region with right, and $\mathrm{Q}$ is the incentive to traffic achievement.

The spectrum fee formula has to include the incentives. Furthermore, the spectrum fee formula has also to make the spectrum utilization optimum, since it is the key point to know that the spectrums are used efficiently. To accomplish it, we need to simulate the formula above consists of incentive factors into techno-economic of provider industry. By simulating the formula, the spectrum utilization can be obtained optimally.

\section{Comparison Existing BHP-F Formula and ITU SM 2012-2 Formula}

By comparing the Existing BHP-F Formula and ITU SM 2012-2 Formula, it is clear that the existing formula will increase rapidly especially to provider which 
has built or will build many BTS to improve its service quality. Simulation of BHP-F calculation below shows that the BHP-F is increasing with the increase of spectrum utilization while the graphic can be seen in Figure 7.

The formula ITU-R SM 2012-2 shown in Figure 8 has other advantages than merely payment stability; it is technology neutral, it considers the opportunity benefit to licence owner of lower and higher frequency band, and it considers the economic value of a region, which show fairness concept.

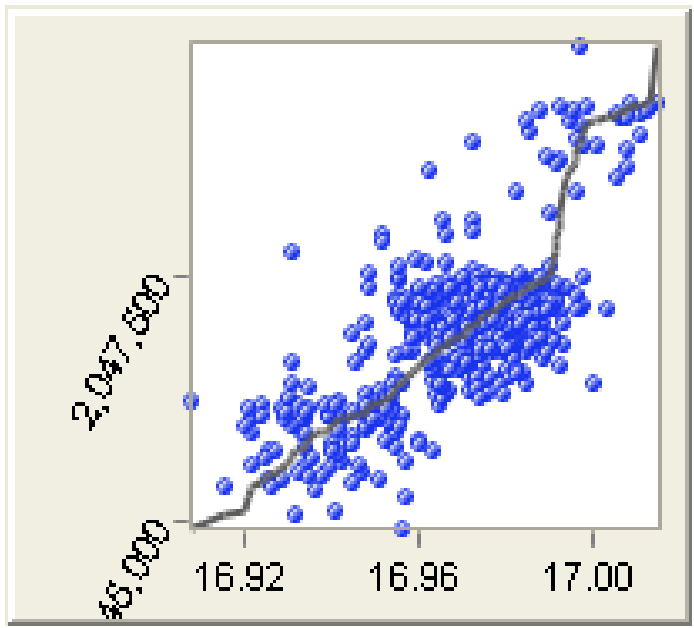

Figure 7 Graphic of BHP-F utilisation (BHP-F Existing).

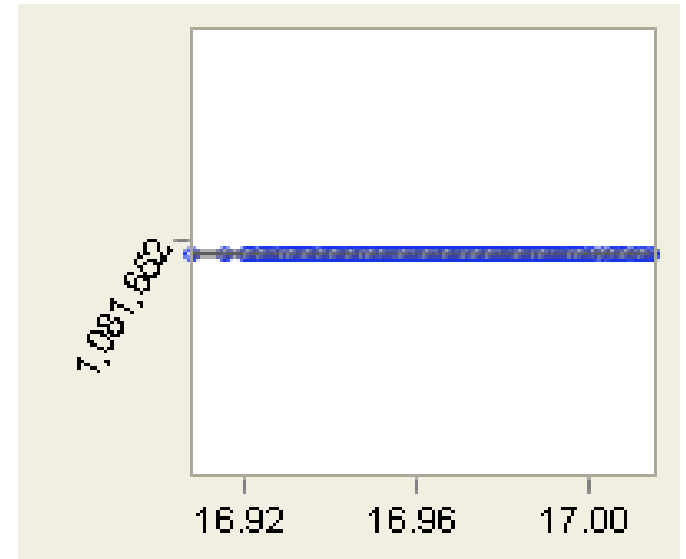

Figure 8 Graphic of BHP-F utilisation (Formula ITU SM 2012-2). 


\section{Conclusion}

It has been shown that the spectrum fee based on the BHP-F formula that is calculated for each station and each RF channel has no ability to promote the efficiency of spectrum usage and to push providers to use the spectrum effectively. Further, it has also no ability to force providers to utilize the spectrum for all part in Indonesia.

It has also been demonstrated that the spectrum fee based on the ITU-R SM 2012-2, which is modified as proposed/new formula of BHP-F, can overcome the problem of BHP-F formula and can provide fairness for every provider since the provider with the same right pays the same price.

Lastly, introducing some incentive scenario could encourage the utilization of spectrum efficiently. Therefore, government should give compensation to the provider that succeeds in achieving higher spectrum utilization.

\section{References}

[1] Cave, M., Doyle, C. \& Webb, W., Essential of Modern Spectrum Management, Cambridge University Press, New York, 2007.

[2] Commonwealth of Australia, Radio communications Inquiry Report, Productivity Commission, Australia, 2002.

[3] Youssef, A.M., Kalman, E. \& Benzoni, L., Technico-Economic Methods for Radio Spectrum Assignment, IEEE Communications Magazine, IEEE, 33(6), 1995.

[4] ITU-R Recommendations SM.1046-2, on Definition of spectrum use and efficiency of a radio system.

[5] ITU-R Recommendations SM.2012-2, on Economic aspect of spectrum management.

[6] Government Regulation No.28 of 2005, Non-Tax Government Revenue On Communication And Information Ministry.

[7] Government Regulation No.53 of 2000, The Use Of A Radio Frequency Spectrum And Satellite Orbit.

[8] ITU-R Recommendation SM.328-9, on Spectra and bandwidth of emissions.

[9] Directorate General of Post and Telecommunications, Study Report of Spectrum Fee in Indonesia, 2008.

[10] ITU-R Recommendation P.1546, Method for point-to-area predictions for terrestrial services in the frequency range $30 \mathrm{MHz}$ to $3.000 \mathrm{MHz}$ 
[11] Yu Hsiao-Cheng, Zon-Yau Lee \& Hung-Yuh Lee, Revising Taiwan's Frequency Usage Fee Regulation, Telecommunication Policy 28 ELSEVIER, 2003. 